\title{
Neonatal Infection in the University Teaching Hospital of Parakou/Benin: Trends in Frequency and Lethality from 2010 To 2016
}

\author{
Agossou J*, Noudamadjo A, Adédémy JD, Agbeille Mohamed F, Kpanidja MG, Zinvokpodo KM, \\ Ahodégnon $\mathrm{R}$
}

University of Parakou, Parakou, Benin

\begin{abstract}
Introduction: In countries with high mortality, as in sub-Saharan Africa, approximately half of the neonatal deaths are attributable to infections. This study aimed to investigate the trends in frequency and lethality of neonatal infections in the University Teaching Hospital of Parakou (CHU-P), from 2010 to 2016.

Patients and methods: This research work is a cross-sectional and descriptive study with retrospective collection of data carried out in the CHU-P Pediatric Unit during the period running from January 1, 2010 to December 31, 2016. It involved newborns admitted to the neonatal intensive care unit during the study period. Main variables were related to neonatal infections.

Results: During the study period, 6204 newborns were registered, including 3530 boys and 2674 girls i.e. a sex ratio of 1.32. Mean age for newborns was $6.01 \pm 5.39$ days. Average frequency of neonatal infection (NNI) was $54.11 \%$, oscillating between $48.87 \%$ in 2010 and $56.91 \%$ in 2015 . Average lethality or mortality rate was estimated at $26.30 \%$, with extremes of $21.12 \%$ in 2013 and $31.58 \%$ in 2012.

Conclusion: More than 5 out of 10 children hospitalized in the neonatal intensive care unit between 2010 and 2016 were diagnosed with a neonatal infection and one out of five newborns died of it. This sometimes justifies the excessive use of antibiotics. Prospective study with appropriate diagnostic tools is necessary to take stock of the actual status of neonatal infection in the hospital's neonatal intensive care unit.
\end{abstract}

Keywords: Neonatal infection; Frequency; Lethality; Benin

\section{INTRODUCTION}

Neonatal mortality is still a major public health issue across the world; it accounts for more than $60 \%$ of child deaths before their first year in life [1,2]. Among the 130 million births registered per year, 4 million deaths of newborns are recorded, including $75 \%$ who die during their first week of life $[3,4]$. In countries with high mortality as the ones in Sub-Saharan Africa, nearly half of the neonatal deaths are attributable to infections [5]. In Burkina Faso, infections are responsible for $37 \%$ of neonatal deaths [6]. The last update released in the hospital unit on this very common disease dates back to eight years, while changes in human resources happened. This is the rationale for the conduct of the present research work which aimed to investigate the trends in frequency and lethality of neonatal infection from 2010 to 2016 in the CHU-P neonatal intensive care unit.

\section{PATIENTS AND METHODS}

This research work is a cross-sectional and descriptive study with a retrospective collection of data carried out in the neonatal intensive care unit of the CHU-P pediatric department in Parakou (Northern Benin). It was conducted over the period running from January 1, 2010 to December 31, 2016 i.e. seven (07) years; it involved all the newborns hospitalized in the neonatal intensive care unit during the study period. To be included, the newborns should have been admitted alive with a health record in which diagnosis and type of discharge were mentioned. This study has excluded all the newborns admitted

Correspondence to: Joseph Agossou, Faculty of Medicine, University of Parakou, Parakou, Benin, Tel: 229 97693677; E-mail: agossoujoseph@gmail.com

Received: September 25, 2019; Accepted: October 10, 2019; Published: October 17, 2019

Citation: Agossou J, Noudamadjo A, Adédémy JD, Mohamed AF, Kpanidja MG, Ahodégnon R, et al. (2019) Neonatal Infection in the University Teaching Hospital of Parakou/Benin: Trends in Frequency and Lethality from 2010 To 2016. Clinics Mother Child Health 16:336. DOI: 10.35248/2090-7214.19.16.336

Copyright: (02019 Agossou J, et al. This is an open-access article distributed under the terms of the Creative Commons Attribution License, which permits unrestricted use, distribution, and reproduction in any medium, provided the original author and source are credited. 
alive, dead on admission or who had no usable health record (including neither diagnosis nor type of discharge). Census was complete; it systematically included all health records of patients meeting the inclusion criteria. The main variables investigated were diagnosis of apparent neonatal infection and hospital discharge pattern of newborns followed up for apparent NNI. The secondary variables were sociodemographic features of parents and newborns. NNI diagnosis was made in accordance with national guidelines mentioned in the emergency obstetric and newborn care (EmONC) training manual [7]. For instance, a newborn was considered as infected if there were infection anamnesis during pregnancy or abnormal physical sign nonattributable to another non-infectious situation (malformation, trauma etc.). In addition, newborn is also considered as infected if there is a biological sign conducive to an infection (C-Reactive Protein above or equal to $12 \mathrm{mg} / \mathrm{l}$, hyperleukocytosis (number of white blood cells estimated at $25000 / \mathrm{mm}^{3}$ or more), leukopenia (number of white blood cells below or equal to $5000 / \mathrm{mm}^{3}$ ), thrombocytopenia (number of platelets below 150000/ $\mathrm{mm}^{3}$ ), whether there were anamnestic signs of infection or not.

Neonatal infection was considered as possible (suspected) when the presence of one of the following anamnestic arguments is noted with physical or biological sign: preterm rupture of membranes (PROM), prolonged rupture of membranes for more than $12 \mathrm{~h}$, notion of urinary or genital infection that was not treated or was poorly treated in the mother within the month preceding childbirth, meconium-stained amniotic fluid without obstetrical explanation, spontaneous preterm birth, acute fetal distress or neonatal resuscitation without explanation. NNI was considered as moderate when only one focus of infection and signs of vital distress are observed. It is labeled as severe when there is at least one sign of vital distress or when there are at least two focuses of infection. Entry, processing, and analysis of data were performed using the software EPI INFO version 7 . Data analysis focused on the description of the different groups of variables characterizing newborns and their parents. The measures of central tendency (Mode and Mean) and dispersions (Standard deviation) were used to describe quantitative variables, and proportions were used for qualitative variables.

\section{Ethical and professional considerations}

The conduct of this study has been authorized in writing by the Director of CHU-P and the Head of the Pediatric Unit, particularly as regards the processing of health records. Data anonymity and confidentiality have been guaranteed.

\section{RESULTS}

\section{Population description}

Information related to parents: The mean age for mothers was $26.3 \pm 9.1$ years. The youngest mother was 14 years and the oldest one 45 years.

Table 1: Distribution of newborns admitted to CHU-P neonatal intensive care unit from 2010 to 2016 according to socio-demographic and anamnestic characteristics $(\mathrm{N}=6204)$.

\begin{tabular}{lll}
\hline & Population size & Proportion (\%) \\
\hline Sex & & \\
\hline Male & 3530 & 56.9 \\
\hline Female & 2674 & 43.1 \\
\hline Age (Days) & & \\
\hline$\leq 1$ & 4529 & 73 \\
\hline $2-7$ & 1110 & 17.89 \\
\hline$>7$ & 565 & 9.11 \\
\hline
\end{tabular}

Birth weight (g)

Very low birth weight 492 $(<1500)$

\begin{tabular}{lll}
\hline Low birth (1500-2499) & 1724 & 27.8 \\
\hline Normal weight (2500-3999) & 3792 & 61.1 \\
\hline Macrosomia ( $\geq 4000)$ & 193 & 3.1 \\
\hline
\end{tabular}

Type of admission

Transferred from the CHU-P 4168

Maternity

Referrals from other health 1228

centers

\begin{tabular}{lcc}
\hline Direct admission & 808 & 13 \\
\hline Pregnancy monitoring & & \\
\hline Yes & 5724 & 92.3 \\
\hline No & 480 & 7.7 \\
\hline
\end{tabular}

Disease in pregnancy

\begin{tabular}{lll}
\hline Yes & 911 & 14.7 \\
\hline Non & 5293 & 85.3 \\
\hline Mode of birth & & \\
\hline Eutocic & 3981 & 64.2 \\
\hline Dystocic & 318 & 5.1 \\
\hline Cesarean section & 1905 & 30.7 \\
\hline
\end{tabular}

Most of the mothers were housewives (58.70\%) and fathers who were craftsmen or workers by profession were the predominant group i.e. $45.60 \% .5360$ out of all the parents lived in the District of Parakou (86.30\%) and 840 outside Parakou (13.70\%). 
Information related to the newborns: 3530 out of all the admitted newborns were boys (59.90\%) and 2674 were girls $(43.10 \%)$ i.e. a sex ratio of 1.32 . On admission, the mean age for newborns was $6.01 \pm 5.39$ days. The youngest newborn was 0 day and the oldest one was 28 days. Mean birth weight (MBW) for newborns was $2608.85 \pm 727.67 \mathrm{~g}$. The lowest weight was $500 \mathrm{~g}$ and highest birth weight was $4900 \mathrm{~g}$. The newborns who were transferred from the CHU-P maternity ward (in-born) were predominant (67.20\%). 5724 out of the 6204 included newborns were born from pregnancy followed-up in accordance with the applicable standards i.e. 92.30\%. Nine hundred and eleven were born from pregnancy punctuated by diseases and ailments (14.70\%) and 3981 were born from eutocic delivery (64.20\%). Table 1 shows newborns' distribution according to pregnancy anamnestic data.

\section{Study of neonatal infections}

Among the 6204 newborns admitted to the neonatal intensive care unit, 5077 had a neonatal infection no matter the type (patent NNI or suspected NNI) i.e. a frequency of $81.83 \% .3357$ out of the 5077 newborns had a patent neonatal infection $(66.10 \%)$ and 1720 had a suspected neonatal infection (33.90\%). Therefore, the average frequency of apparent NNI over the seven years of study was 54.11\%. Among the 3357 newborns presenting with apparent NNI, those admitted in 2015 and in 2016 to the neonatal intensive care unit were predominant i.e. respectively $57.62 \%$ and $57.53 \%$. Table 2 shows the distribution of infected newborns according to year of admission.

Table 2: distribution of infected newborns admitted from 2010 to 2016 to the CHU-P neonatal intensive care unit according to the year of admission, $(\mathrm{N}=6204)$.

\begin{tabular}{|c|c|c|c|}
\hline & $\begin{array}{l}\text { Number of annual } \\
\text { admissions }\end{array}$ & $\begin{array}{l}\text { Number of } \\
\text { NNI cases per } \\
\text { year }\end{array}$ & $\begin{array}{l}\text { NNI frequency per } \\
\text { year }\end{array}$ \\
\hline 2010 & 789 & 385 & 48.87 \\
\hline 2011 & 816 & 453 & 55.5 \\
\hline 2012 & 1004 & 540 & 53.78 \\
\hline 2013 & 1052 & 542 & 51.47 \\
\hline 2014 & 1008 & 564 & 55.98 \\
\hline 2015 & 748 & 426 & 56.91 \\
\hline 2016 & 787 & 447 & 56.81 \\
\hline
\end{tabular}

2293 out of the 3357 infected newborns had a severe neonatal infection (68.30\%) and 1064 had moderate neonatal infection (31.70\%). Concerning infection locations, 1467 out of the 3357 infected newborns had infections with inaccurate location (43.70\%); 647 had lung infection (19.30\%); 367 had enterocolitis (10.90\%); 283 had neonatal meningitis $(8.40 \%)$; 182 had omphalitis (5.40\%); 174 had systemic infection $(5.20 \%)$, 144 had skin infection (4.30\%); 51 had urinary infection
(1.50\%) and 42 had other specific infections (1.30\%). During the seven (07) years of study, 883 out of the infected newborns died i.e. an NNI-related median lethality estimated at $26.30 \%$. Mortality associated with NNI was rated $14.23 \%(883 / 6204)$ during the seven years. Lethality and mortality related to NNI were predominant in 2012. Figure 1 displays the distribution of lethality and mortality associated with newborns' NNI according to different years.

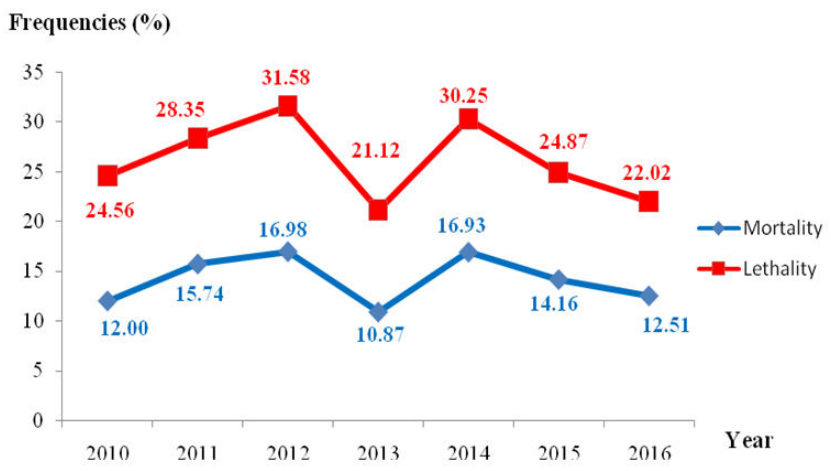

Figure 1: Distribution of newborns admitted to the CHU-P neonatal intensive care unit from 2010 to 2016 depending on lethality and mortality associated with NNI.

\section{DISCUSSION}

This cross-sectional study based on a retrospective collection of data was carried out in the CHU-P neonatal intensive care unit over a seven-year period. It has allowed for an in-depth analysis of the outcome of neonatal infections over time. The completeness of clinical and paraclinical information thus collected is a methodological key point; in addition, it helps reduce information bias. Its retrospective nature is indeed a source of possible missing data, but it has the merit of addressing this health issue on such a large number of subjects.

\section{Socio-demographic, clinical and paraclinical features of parents and newborns}

The mean age for mothers was $26.3 \pm 9.1$ years. The youngest one was 14 years and the oldest one 45 years. Mothers aged 20 to 35 years were predominant $(81.10 \%)$. This maternal age group is indeed the most sexually active age range, and therefore fit for procreation. This result is similar to the one reported by Nagalo et al. in the El Fatheh-Suka Clinic in 2013 in Ouagadougou (Burkina Faso) [8]. Most of the mothers were housewives (58.70\%) and $68.70 \%$ of fathers were farmers and craftsmen/ workers. Actually, in developing countries the professions mentioned just above are most common in a large segment of the population which is illiterate and with very low purchasing power. These findings are identical to the ones encountered by Noudamadjo et al. in CHU-P in 2012 [9]. Most of those parents lived in the city of Parakou. For instance, in this study, $86.30 \%$ of admissions originated from the city of Parakou vs. $13.7 \%$ outside Parakou. Therefore, the neonatal intensive care unit is primarily used by the local population while it is also a unit with provincial and even regional scope. This raises and points out the geographic accessibility issue; therefore, there is need to consider putting in place neonatal intensive care units within all 
the zone hospitals of Borgou and Alibori regions with adequate staff and equipment. These results are consistent and similar to the ones obtained by Noudamadjo et al. in 2012 in the same hospital unit [9]. We noted a slight predominance of boys among the population of children investigated in this study. This male predominance would be due to the fact that male newborns are more vulnerable. In this study, the sex ratio was close to the ones found by other authors in the sub-region. Such is the case for Amorissani et al. in 2006 in the University Teaching Hospital of Cocody (Abidjan/Côte d'Ivoire) [10], Akaffou et al. in 2009 in the University Teaching Hospital of Yopougon (Abidjan/Côte d'Ivoire) [11], Nagalo et al. in 2013 at the El Fatheh-Suka Clinic [8], Noudamadjo et al. in 2012 in CHU-P [9]. Considering all the admissions, $73 \%$ of newborns were admitted within the first 24 h of life i.e. more than $2 / 3$ of admissions. This result may be due the fact that most newborns admitted to the neonatal intensive care unit of the pediatric department came from the maternity ward of the same hospital. Actually, that maternity is a third referral center that attends cases of complications in childbirth and pathological pregnancies with their associated real or potential neonatal morbidity that require early hospitalization of newborns immediately after their birth. Those sick newborns often present with signs of vital distress within the first $24 \mathrm{~h}$ of life, hence the need to provide them close monitoring during the first hours and first days of life. Newborns with low birth weight were predominant (more than 1/3) but there were also some cases of macrosomia. Classically, newborns with low birth weight are exposed to higher risk of death; therefore, it is necessary to develop policies for the prevention of low birth weights within the local communities. These preventive measures shall consist of improving the health of women in child-bearing age and pregnancy monitoring. This result is similar to the one reported by Nagalo et al. who found in their research work $56.90 \%$ of eutrophic newborns, $40.20 \%$ of low birth weights and $2.90 \%$ of macrosomic infants [8]. The fact that the neonatal intensive care unit is close to the CHU-P maternity facilitated the instantaneous transfer of many newborns; this helped provide them quick care. This high rate of newborns transferred from the CHU-P maternity suggests that it is necessary to develop and strengthen collaboration between both health facilities in order to improve newborns' survival. As regards the admissions, our results are similar to the ones found out by Nagalo et al. who reported that $72.30 \%$ of admissions were received after direct transfer from the maternity, $20.4 \%$ after transfer from the pediatric emergency unit and $7.30 \%$ after regular medical consultation at the El Fatheh-Suka Clinic in 2013 [8].

\section{Frequency of neonatal infections and lethality}

In this study, neonatal infections were the most common disease, with $54.11 \%$ of admissions. Frequency reached a peak in 2015 (56.91\%) and was at its lowest level in 2010 (48.87\%) but overall, approximately one out of two newborns admitted to the unit was attended for NNI, thereby showing a stable situation over the years, in terms of frequency. This frequency is lower than the one reported in a study conducted in Burkina Faso in 2015 by Ouédraogo et al. who estimated NNI frequency at $76.02 \%$ [2]. This high frequency of neonatal infections found in our study may be due either to poor pregnancy monitoring and lack of asepsis during childbirth or to newborn septic handling. For instance, in addition to classical maternal-fetal infections, the traditional practices consisting in making the umbilical cord fall off before the $72 \mathrm{nd}$ hour of life would predispose those newborns to have infections with umbilical cord as entry point. This may also be explained by the sensitivity and specificity of diagnostic tools since microbiology is relatively underdeveloped in our hospital. This may lead to making an inaccurate diagnosis of neonatal infections. This situation underlines the importance of developing microbiology as an exploration technique in order to reduce antibiotic pressure, and selection of resistant bacteria. And, as a result, the same situation highlights the necessity to improve the quality of case management. The findings of this study are identical to those of Noudamadjo et al. suggesting that $57.80 \%$ of hospitalizations were decided for neonatal infections [9]. The predominance of neonatal infections among the diseases of the newborn has been reported by many African authors, but with different morbidity rates. Kedy Koum et al. found out $62 \%$ [12], Thomson et al. found out $63.70 \%$ [13]. Some authors reported lower rates. These are Nagalo et al. who found $23.50 \%$ and Akaffou et al. 30.30\% [8,11]. The traditional practices related to infant health care associated with poor standards of hygiene, increase the risk for umbilical cord infection and even the risk of neonatal tetanus. Agossou et al. made those same observations regarding umbilical care for newborns in a community-based study conducted in Parakou in 2013 [14]. The same remark was made by Amorissani et al. who showed that neonatal morbidity related to traditional care was dominated by umbilical infections in $65.20 \%$ of cases [10]. In this study, NNI-related lethality was estimated at $26.30 \%$. This slightly increased rate was found during in-hospital studies conducted in Africa [15]. These results may be explained by a shortage of permanent medical staff in the neonatal intensive care unit and inadequacy of diagnostic and therapeutic resources. In contrast, a rate that is lower $(9.00 \%)$ than the one of this study was found in a research work conducted in Burkina Faso [2]. The declining annual chronological trends in the rate of mortality associated with NNIs would be attributable to the implementation of the Emergency Obstetric and Newborn Care (EmONC) strategy by the Government of Benin since 2002. This decrease may also be due to new measures for infection prevention related to care, applicable in the neonatal intensive care unit since 2014 . As a matter of fact, lethality associated with NNIs reached a peak in 2012 (31.58\%) before declining in 2016 (22.02\%).

\section{CONCLUSION}

In brief, more than five out of ten children admitted to the CHU-P neonatal intensive care unit from 2010 to 2016, were hospitalized for neonatal infection. Certainly, there are factors associated with the high frequencies of neonatal infection noted among newborns. A further study is required to have an indepth knowledge of those determinants in order to better grasp the real causes of this scourge affecting the newborns. 


\section{REFERENCES}

1. Ezeh OK, Agho KE, Dibley MJ, Hall J, Page AN. Determinants of neonatal mortality in Nigeria: Evidence from the 2008 demographic and health survey. BMC Public Health. 2014;14 521.

2. Ouédraogo SYO, Yougbaré N, Kouéta F, Ouédraogo M, Lougué C, Traoré OR, et al. Analysis of newborn care within the framework of the national strategy of subsidies for childbirths and emergency obstetric \& newborn care in the Charles de Gaulle Pediatric University Teaching Hospital, Ouagadougou (Burkina Faso). Pan Afr Med J. 2015;20: 176.

3. Lawn J, Cousens S. Four million neonatal deaths: When? Where? Why? Lancet. 2005;365: 891-900.

4. Zupan J. Perinatal mortality in developing countries. N Engl J Med. 2005;352: 2047-2048.

5. Blencowe $\mathrm{H}$, Cousens $\mathrm{S}$. Addressing the challenge of neonatal mortality. Trop Med Int Health. 2013;18(3): 303-312.

6. United Nations Children's Fund (UNICEF). Country profile, Burkina Faso: maternal, Newborn \& child survival. Geneva: UNICEF;2012.

7. Ministry of Health of Benin. Directorate of mother and child health. Training manual for emergency obstetric and new-born care (EmONC). Participant Handbook. 2015;p: 325.

8. Nagalo K, Dao F, Housseini FT, Diarra Y. Morbidity and mortality of newborns hospitalized over 10 years in the El Fateh-Suka Clinic (Ouagadougou, Burkina Faso). Pan Afr Méd J. 2013; 14: 153.
9. Noudamadjo A, Agossou J, Adédémy JD, Koussihouedé C, Ayivi B. Neonatal morbidity and mortality from 2002 to 2009 in the CHD-B neonatal intensive care unit (BENIN). Annales de l'Université de Parakou. 2012;2(2): 23-27.

10. Amorissani MF, Kouakou C. Morbidity and mortality related to traditional care among newborns in the university teaching hospital (CHU) of Cocody/Abidjan. Cahier Santé Publique 2006;5: 68-75.

11. Akaffou A, Dick AF, N'gucssan R. Epidemiological study of malaria during the neonatal period in the university teaching hospital of Yopougon, Abidjan/Republic of Côte d'Ivoire. Mali Médical. 2009;24(3): 36-39.

12. Koum DCK, Essomba NE, Ngaba GP, Sintat S, Ndombo PK, Coppieters Y. Morbidity and risk factors for neonatal mortality in a referral hospital of Douala. Pan Afr Méd J. 2015;20: 258.

13. Thomson J, Schaefer M, Camino AB, Kahindi D, Hurtado N Burkina improved neonatal mortality at a district hospital in aweil, South Sudan. J Top Pediatr. 2017;63(3): 189-195.

14. Agossou J, Hounnou-d'Almeïda M, Adédémy JD, Noudamadjo A, N'gobi DYG, Ayivi B, et al. Newborn umbilical cord care in parakou in 2013: Practice and risks. Open J Ped. 2016; 6: 124-135.

15. Bezzaoucha A, El-Kebboub A, Aliche A. Outcome of neonatal mortality in the university teaching hospital (CHU) of Blida (Algeria) from 1999 to 2006. Bull Soc Pathol Exot. 2010;103: 29-36. 